\title{
Self, partner, and relationship motivations for healthy and unhealthy behaviors
}

\section{BACKGROUND}

This study merges two theoretical paradigms: self-determination theory and interdependence theory. The primary objective was to examine whether people in relationships are motivated to enact healthy or unhealthy behaviors based on personal (i.e., autonomous) or interpersonal (controlled) motives.

\section{PARTICIPANTS AND PROCEDURE}

We tested the sources of healthy and unhealthy motivation in a cross-sectional, dyadic survey, collecting data from 243 couples in romantic relationships. Survey items assessed sources of healthy and unhealthy motivational influence, including the self, partner, and relationship, in conjunction with relationship satisfaction and well-being. Data were analyzed according to the Actor Partner Interdependence Model to examine intrapersonal and interpersonal associations between variables.

\section{RESULTS}

Healthy and unhealthy behavior motivation appears to be a relational, rather than individual construct. Partner healthy motivation was positively associated with individuals' relationship satisfaction. For individuals who reported more unhealthy relationship motivations, relationship satisfaction and well-being were lower. There were no significant associations for self motivations.

\section{CONCLUSIONS}

The findings suggest that relational partners and the romantic relationship itself are important in understanding the dimensions of health motivation for people in relationships. We conclude that the romantic relationship context impacts health maintenance, supporting the merging of personal and interpersonal motivations for health behaviors.

\section{KEY WORDS}

well-being; motivation; quality of the relationship; health influence

ORGANIZATION - 1: Hanover College, USA · 2: Texas State University, USA

AUthors' CONTRiButions - A: Study design - B: Data collection · C: Statistical analysis · D: Data interpretation ·

E: Manuscript preparation · F: Literature search · G: Funds collection

CORRESPONDING AUthor - Valerie J. Young, Ph.D., Hanover College, 517 Ball Drive, 47243 Hanover, USA,

e-mail: youngv@hanover.edu

TO CITE THIS ARTICLE - Young, V. J., \& Burke, T. J. (2017). Self, partner, and relationship motivations for healthy

and unhealthy behaviors. Health Psychology Report, 5(3), 219-226. doi: https://doi.org/10.5114/hpr.2017.65221

RECEIVED 06.09.2016 - REVIEWED 19.10.2016 - ACCEPTED 22.11.2016 · PUBLISHED 26.01.2017 


\section{BACKGROUND}

People are motivated to engage in healthy or unhealthy behaviors for a variety of reasons, from personal enjoyment of exercise or indulgent foods to sharing healthy or unhealthy interests or activities with their romantic partners. Involvement in a romantic relationship serves as a built-in mechanism for health behavior influence, as couples often share eating, exercise, and weight gain patterns (Burke, Beilin, Dunbar, \& Kevan, 2004; Craig \& Truswell, 1990). Indeed, research indicates that people are motivated to engage in healthy behaviors as a function of social influence from their relational partner (Lewis \& Butterfield, 2007; Markey, Markey, \& Gray, 2007). It is important to understand more about how partners communicate this influence in regards to healthy and unhealthy behaviors, as these behaviors have the potential to either prevent or contribute to the development of serious health conditions. Cardiovascular disease, for example, is the leading cause of death among both men and women in the U.S., but can be prevented by making healthy lifestyle choices (Centers for Disease Control and Prevention, 2015).

The current study merges two theoretical paradigms, self-determination theory and interdependence theory, in order to explore sources of personal and interpersonal motivation. Self-determination theory (SDT; Deci \& Ryan, 1985) posits that individuals may be internally or externally motivated for health behavior change. This theory stipulates that although external motives exist, people are typically self-motivated to engage in behavior changes (Deci \& Ryan, 2008). Alternatively, previous research suggests that an overwhelming majority of married couples (95\%) reportedly try to influence or regulate their partner's health behaviors (Lewis \& Butterfield, 2007). In contrast to SDT, interdependence theory (Thibaut \& Kelley, 1959) offers a relational emphasis for motivation and relational outcomes. Thus, we aim to extend SDT to a relational context by examining how healthy and unhealthy motivation from one's self, partner, and relationship contributes to well-being and relationship satisfaction.

\section{SELF-DETERMINATION THEORY}

Self-determination theory (Deci \& Ryan, 1985) explains that people have distinct motives for behaving in healthy ways: autonomous motivation and controlled motivation. Autonomous motivations are the intrinsic, or internally driven, values activated when a person believes that a certain activity has personal importance. These motivations are considered volitional, or under the control of the self, and are integrated into one's sense of self. The second type of motivation identified in SDT, controlled motivation, represents behavior driven by a reward or punishment from a source outside the self. Common examples of controlled motivation include fear of rejection by others, and a desire to obtain rewards or approval for a behavior. Although both autonomous and controlled motivations are effective in yielding behavioral outcomes, autonomous motivations tend to be associated with psychological health and long-term healthy behavior persistence (Deci \& Ryan, 2008).

With regard to diet and exercise behaviors specifically, intrinsic motivation to exercise is associated with females' exercise enjoyment, perceived competence in exercise, and effort made to exercise (Boyd, Weinmann, \& Yin, 2002). These intrinsic exercise goals are also associated with other positive outcomes, including self-worth, well-being, and exercise behavior (Sebire, Standage, \& Vansteenkiste, 2009). Accordingly, exercise interventions using an intrinsic motivation approach, have been developed to instill a sense of self-motivation in school education programs (Moreno, Gonzalez-Cutre, Martin-Albo, \& Cervello, 2010). In addition to exercise behaviors, increased feelings of self-determination and motivation can help women self-regulate their eating (Mata et al., 2009). The aforementioned research indicates that individuals who perceive some inherent personal value in a behavior will be more likely to engage in behaviors congruent with autonomous motivations. Thus, self-motivation for healthy behaviors should positively impact one's own well-being.

Alternatively, research examining external sources of motivation in SDT is limited. In a review of health promotion research, Dunsmore and Goodson (2006) note that some scholars argue that externally motivated health behaviors, or those which are performed for some reason other than personal enjoyment or desire, can still be somewhat valuable in predicting health behaviors but may not be closely tied to health or well-being. Much can be learned, however, from the perspective of interpersonal health communication and social influence about how one's romantic partner or relationship can act as a motivating factor for health behaviors and whether autonomous or controlled motivations could impact a person's relationship satisfaction, in addition to well-being.

\section{INTERDEPENDENCE THEORY}

Interdependence theory (Thibaut \& Kelley, 1959) accounts for behaviors enacted with a relational partner in mind. The theory posits that individuals who are involved in an interdependent relationship will be likely to influence each other's behaviors, and in turn these individuals transform their own motivations to best meet the needs of their partners and their relationship. These transformations represent external, other-centered motivations, and are often 
associated with positive relationship outcomes, such as increased satisfaction and commitment (Powell \& Van Vugt, 2003; Rusbult, Arriaga, \& Agnew, 2001). Transformations of motivation are most likely to occur when an individual is in a satisfying, stable relationship with another person (Kelley \& Thibaut, 1978), and enacting transformations has personal benefits, as well as partner well-being benefits (Van Lange et al., 1997).

Interdependence theory's transformations of motivation supplement SDT by providing the framework for understanding how people may be motivated to make healthy or unhealthy decisions for the sake of their partner or relationship (i.e., due to an external motivation). For example, people in relationships often end up changing their eating or exercise habits to maintain harmony and align with a partner's wishes (Craig \& Truswell, 1990; Hong et al., 2005; Treiber et al., 1991). Social control research indicates that couples do engage in health-enhancing social influence and that relational partners perceive this influence in their relationships (Burke \& Segrin, 2016); however, the current study is focused on understanding partners' identification of relational motives for their health behaviors.

These transformations of motivation may involve aligning not only healthy behaviors, but also unhealthy ones (Craig \& Truswell, 1990). For many couples, relationship transition points, such as cohabitation, marriage, and childbirth, are associated with decreased physical activity, changes in eating patterns and serving sizes, and weight gain (Burke et al., 2004). The extant research primarily examines individuals' health behaviors; however, the current study examines the sources of healthy and unhealthy motives in conjunction with relationship satisfaction and well-being.

\section{SELF, PARTNER, AND RELATIONSHIP MOTIVATIONS}

Taken together, self-determination and interdependence theories provide a more comprehensive view of how one's healthy and unhealthy motivations can be attributed to multiple sources: themselves, their partner, or their relationships in general. We argue that the theories should be integrated and extended to test a model of personal and interpersonal health motivations among people in romantic relationships. As the basis for our theoretical integration, SDT lays the groundwork for understanding internal and external sources of motivation. Further, drawing upon the ideas of partner influence and transformations of motivation from interdependence theory, we aim to extend elements of SDT to understand relational (i.e., controlled) sources of healthy and unhealthy motivations.

Although SDT would suggest that such relationally oriented controlled motivation might not be as effective as autonomous (i.e., self) motivations, the literature on interdependence theory suggests that when individuals make behavior changes for a significant other, it can be intrinsically rewarding and positively impact their relationship satisfaction. The literature on unhealthy motivations is scarce, and we cannot ascertain how well-being or relationship satisfaction might be impacted when people in relationships identify their sources of motivation. Therefore, we pose the following research questions to investigate associations of healthy and unhealthy motivation sources, relationship satisfaction, and well-being. RQ1: What is the effect of the source of healthy motivations (RQ1a) or unhealthy motivations (RQ1b) in predicting personal well-being?

RQ2: What is the effect of the source of healthy motivations (RQ2a) or unhealthy motivations (RQ2b) in predicting relationship satisfaction?

\section{PARTICIPANTS AND PROCEDURE}

\section{PARTICIPANTS}

Participants were 486 people in relationships (including 241 matched male/female couples), aged 18 to 71 years old $(M=32.08, S D=13.48)$, and with an average relationship length of just under nine years ( $M=8.98, S D=11.11$, range 4 months to 44.5 years). About half of the sample consisted of never-married individuals (49.79\%), and $35.68 \%$ were in their first marriage. Others were in their second marriage $(6.85 \%)$ or divorced $(5.39 \%)$. A few were in their third marriage $(1.24 \%)$, separated $(0.62 \%)$, or widowed $(0.41 \%)$. A majority of the sample $(62.66 \%)$ reported living with their partner full time, and under half (41.88\%) had children.

Participant education level included less than high school (1.24\%), high school diploma (10.35\%), some college $(41.41 \%)$, trade or vocational school training (4.14\%), a college degree (25.47\%), postgraduate work $(4.55 \%)$ or postgraduate degree $(12.84 \%)$. Income was fairly evenly distributed across the sample, with $44.40 \%$ reporting under $\$ 50,000$ (USD) annual income, $24.74 \%$ reporting $\$ 50,000-100,000$, and $30.87 \%$ over $\$ 100,000$. Most were employed full time $(47.30 \%)$, part time (17.01\%), or were current students $(24.48 \%)$. The sample was $77.45 \%$ European American, with $11.90 \%$ Hispanic/Latino, 4.18\% African American, 3.76\% more than one race or ethnicity, and less than $3.00 \%$ were Asian, Pacific Islander, or American Indian.

\section{PROCEDURES}

Data were collected using self-report cross-sectional online surveys distributed in two ways. Participants were recruited either through student referral
Healthy and unhealthy motivations 
Valerie J. Young, Tricia J. Burke
( $n=444)$, or through survey advertisements posted on Craigslist.com $(n=42)$. To participate in the Institutional Review Board approved study, individuals had to be over 18 years old and involved in a romantic relationship. Both individuals in the couple were asked to complete the survey, and only the data from participants with partner data were included in the final sample (486 of 670 invited individuals, $72.54 \%$ response rate). Students were offered extra credit for referring a couple to complete the study or participating themselves if they met the study criteria; non-student participants were offered a $\$ 10$ gift card. In the final sample $29.05 \%$ of individuals were enrolled as full or part-time college students.

\section{MEASURES}

Participants completed self-report measures of healthy and unhealthy motivations, general well-being, and relationship satisfaction. Correlations are presented in Table 1.

Healthy motivations were assessed using three separate items delineating three different sources of motivations for health maintenance behaviors. Participants were asked, "To what extent do you work to maintain your health for yourself (to improve your physical well-being, because you enjoy certain healthy activities, etc.)?”. Response options ranged from 1 (not at all) to 4 (all health maintenance done for self), $M=3.01, S D=0.71$. The second item asked, "To what extent do you work to maintain your health for your partner (because your partner wants you to be healthy)?". Response options ranged from 1 (not at all) to 4 (all health maintenance done for partner), $M=2.25, S D=0.68$. The final item asked, "To what extent do you work to maintain your health for your relationship (because you want to improve or maintain your relationship, do healthy things together, etc.)?”. Response options ranged from 1 (not at all) to 4 (all health maintenance done for your relationship), $M=2.37, S D=0.77$.

Three questions were adapted to gauge the level of self, partner, and relationship influence in regards to unhealthy behaviors. Response options were similar to the healthy motivations, with the phrase "all unhealthy behaviors" substituted for "health maintenance" in the frequency labels. Participants were asked, "To what extent does your health suffer because of: yourself (because you personally do not enjoy healthy eating, exercising, etc.)? $(M=2.66$, $S D=0.93)$, your partner (because your partner does not like healthy eating, exercising, etc.)? $(M=1.57$, $S D=0.72$ ), and your relationship (because you and your partner engage in unhealthy or sedentary activities together $)$ ? $(M=1.57, S D=0.72)$ ".

Well-being was assessed using 5 items addressing general well-being, including physical limitations, physical and mental health, and pain adapted from the Medical Outcomes Scale Sf-36 (Ware \& Sherbourne, 1992), where higher scores indicate better overall quality of life, including physical and mental well-being, such as "So far I have gotten the important things I want in life". Response options ranged from 1 (strongly disagree) to 7 (strongly agree), $M=5.34, S D=1.27$, range $1-7, \alpha=.90(\alpha=.89$ men, $\alpha=.90$ women). Relationship satisfaction was assessed using nine items from Rusbult, Martz, and Agnew (1998), such as "My relationship is close to ideal," rated on a 1 (strongly disagree) to 7 (strongly agree) Likert-type scale, $M=5.96, S D=1.23, \alpha=.96(\alpha=.96$ men, $\alpha=.96$ women).

General health status was included as a control variable in the analyses, and was assessed using a single item, "My overall health is" and responses included: poor $(n=2,0.42 \%)$, fair $(n=67,14.02 \%)$, good $(n=257,53.77 \%)$, excellent $(n=152,31.80 \%)$, $M=3.17, S D=0.67$.

Table 1

Correlations among study variables

\begin{tabular}{|c|c|c|c|c|c|c|c|c|}
\hline Variables & 1 & 2 & 3 & 4 & 5 & 6 & 7 & 8 \\
\hline 1. $\mathrm{H}$ self & - & -.01 & $.16^{*}$ & .07 & -.09 & -.04 & .06 & -.01 \\
\hline 2. $\mathrm{H}$ partner & .02 & - & $.52^{* * *}$ & -.08 & $.13^{*}$ & -.01 & .12 & $.28^{* * *}$ \\
\hline 3. $\mathrm{H}$ relationship & .11 & $.58^{* * *}$ & - & -.03 & .05 & .01 & .10 & $.16^{*}$ \\
\hline 4. UH self & .01 & -.07 & -.09 & - & .07 & $.15^{*}$ & -.02 & -.83 \\
\hline 5. UH partner & -.10 & -.08 & -.12 & .01 & - & $.71^{* * *}$ & $-.18^{* *}$ & $-.13^{*}$ \\
\hline 6. UH relationship & -.08 & -.02 & -.07 & .12 & $.74^{* * *}$ & - & $-.20^{* *}$ & $-.23^{* * *}$ \\
\hline 7. Well-being & .11 & .12 & $.25^{* * *}$ & -.07 & -.12 & $-.18^{* *}$ & - & $.62^{* * *}$ \\
\hline $\begin{array}{l}\text { 8. Relationship } \\
\text { satisfaction }\end{array}$ & .10 & $.24^{* * *}$ & $.27^{* * *}$ & -.07 & $-.35^{* * *}$ & $-.31^{* * *}$ & $.56^{* * *}$ & - \\
\hline
\end{tabular}

Note. $\mathrm{H}$ - healthy motives; UH - unhealthy motives. Scores above the diagonal are among women and scores below the diagonal are for men. ${ }^{*} p<.05,{ }^{* *} p<.01,{ }^{* *} p<.001$. 


\section{DATA ANALYSIS}

The associations between sources (i.e., self, partner, relationship) of healthy and unhealthy motives and well-being (RQ1) and relationship satisfaction (RQ2) were examined in multilevel models using SAS PROC mixed. In addition to accounting for the interdependence among our participants (i.e., individuals nested in couples) using these multilevel models, we examined both actor (individual) and partner (interpersonal) effects using Kenny, Kashy, and Cook's (2006) Actor Partner Interdependence Model (APIM) technique. The first model testing RQ1a specified well-being as the dependent variable, and included actor and partner ratings of healthy motivations from the self, partner, and relationship (6 predictors). The second model testing RQ1b was the same, except it included ratings of unhealthy motivations. The third and fourth models specified relationship satisfaction as the dependent variable, and tested RQ2a (same pre- dictors as RQ1a) and RQ2b (same predictors as RQ1b) respectively. Participant age, sex, and health status were included as control variables in all models.

\section{RESULTS}

RQ1 examined the association between healthy and unhealthy sources of motivations and well-being and RQ2 examined the association between healthy and unhealthy sources of motivations and relationship satisfaction. The results presented in Table 2 suggest that individuals reported greater relationship satisfaction as their own and their partner reports of seeing each other as sources of healthy motivation increased, and slightly higher well-being when their partners' reports of seeing them as a source of healthy motivation increased. Conversely, individuals reported lower well-being and less relationship satisfaction as their perceptions that their relation-

Table 2

APIM results for healthy and unhealthy motivation sources and associations with well-being (models 1 and 2) and relationship satisfaction (models 3 and 4)

\begin{tabular}{|c|c|c|c|c|c|c|c|c|c|c|}
\hline & \multirow{2}{*}{ Independent variable } & \multirow{2}{*}{$\mathrm{ICC}$} & \multicolumn{4}{|c|}{ Actor effect } & \multicolumn{4}{|c|}{ Partner effect } \\
\hline & & & Estimate & $S E$ & $t$ & $d f$ & Estimate & $S E$ & $t$ & $d f$ \\
\hline \multirow{3}{*}{ Model 1} & $\begin{array}{c}\text { Healthy Motivation, } \\
\text { Self }\end{array}$ & & -.01 & .09 & -0.16 & 327 & .08 & .09 & 0.89 & 327 \\
\hline & $\begin{array}{l}\text { Healthy Motivation, } \\
\text { Partner }\end{array}$ & $.44^{* * *}$ & .03 & .11 & 0.32 & 336 & .21 & .11 & $1.93^{m}$ & 335 \\
\hline & $\begin{array}{l}\text { Healthy Motivation, } \\
\text { Rel. }\end{array}$ & & .13 & .10 & 1.41 & 326 & .09 & .10 & 0.91 & 326 \\
\hline \multirow{3}{*}{ Model 2} & $\begin{array}{c}\text { Unhealthy Motivation, } \\
\text { Self }\end{array}$ & & .06 & .07 & 0.87 & 354 & -.06 & .07 & -0.88 & 350 \\
\hline & $\begin{array}{c}\text { Unhealthy Motivation, } \\
\text { Partner }\end{array}$ & $.43^{* * *}$ & .01 & .13 & 0.06 & 331 & -.06 & .13 & -0.44 & 338 \\
\hline & $\begin{array}{c}\text { Unhealthy Motivation, } \\
\text { Rel. }\end{array}$ & & -.29 & .12 & $-2.38^{*}$ & 352 & -.02 & .12 & -0.17 & 357 \\
\hline \multirow{3}{*}{ Model 3} & $\begin{array}{c}\text { Healthy Motivation, } \\
\text { Self }\end{array}$ & & -.03 & .09 & -0.39 & 325 & .16 & .09 & $1.85^{m}$ & 325 \\
\hline & $\begin{array}{l}\text { Healthy Motivation, } \\
\text { Partner }\end{array}$ & $.44^{* * *}$ & .38 & .10 & $3.80^{* * *}$ & 335 & .28 & .10 & $2.85^{* *}$ & 333 \\
\hline & $\begin{array}{l}\text { Healthy Motivation, } \\
\text { Rel. }\end{array}$ & & .04 & .09 & 0.45 & 324 & -.04 & .09 & -0.54 & 324 \\
\hline \multirow{3}{*}{ Model 4} & $\begin{array}{c}\text { Unhealthy Motivation, } \\
\text { Self }\end{array}$ & & .01 & .06 & 0.07 & 346 & .01 & .06 & 0.07 & 341 \\
\hline & $\begin{array}{c}\text { Unhealthy Motivation, } \\
\text { Partner }\end{array}$ & $.48^{* * *}$ & -.16 & .12 & -1.38 & 321 & .04 & .12 & 0.37 & 329 \\
\hline & $\begin{array}{c}\text { Unhealthy Motivation, } \\
\text { Rel. }\end{array}$ & & -.26 & .12 & $-2.25^{*}$ & 343 & -.02 & .12 & -0.14 & 349 \\
\hline
\end{tabular}

Note. ${ }^{m} p<.07,{ }^{*} p<.05,{ }^{* *} p<.01,{ }^{* *} p<.001$. ICC - Intraclass correlation (or the proportion of the variance explained in dependent variable by couple membership). Control variables included age, sex, and health status. 
Valerie J. Young, Tricia J. Burke ship was a source of unhealthy motivation increased. One marginally significant association emerged for self-motivation, indicating that these motivations are predominantly relational in nature, and that being other-motivated is associated with greater well-being and relationship quality.

The significant control variables in each analysis were as follows: age was significant and negatively associated in relationship satisfaction models; health status was significant and positive in all models; sex was not significant in any models.

\section{DISCUSSION}

In this study, we explored how internal and relational sources of health behavior motivations can differentially impact well-being and relationship satisfaction. While some previous research and theorizing suggest that internal motivations may be more relevant for sustaining health behavior changes long term, the results of this cross-sectional investigation suggest that external motivations from the partner and relationship are also important to consider in regards to people's well-being and relationship satisfaction.

\section{HEALTHY MOTIVATIONS}

Individuals and their partners reported greater relationship satisfaction as their perceptions that their partners were a source of healthy behavior motivations increased. This finding is consistent with research suggesting that positive influence from one's partner is associated with positive relationship quality (Markey et al., 2007). It is possible that people in better functioning relationships want to sustain these relationships, and therefore encourage their partners to be healthier. Moreover, individuals' detection of their partners' care and concern for their health might signal a relational assurance, which could also be associated with their relationship quality (Canary \& Stafford, 1992).

Individuals tended to report greater well-being as their partners' reports of seeing them as a source of healthy motivations increased (i.e., a marginally significant partner effect for partner motivation). This particular finding could illustrate one of two things, although we emphasize the marginal nature of this effect. First, it is not surprising that people saw their partners as a source of health-related motivation given research indicating that partners often encourage each other to be healthier (Lewis \& Butterfield, 2007). In this case, it could be that those with greater well-being are more likely to extol the virtues of healthy behaviors to their partners because they have firsthand experience of a healthy lifestyle. Thus, their partners see them - and their positive well-being - as a source of healthy motivation. Secondly, it could be that individuals engage in self-persuasion as a function of trying to motivate their partners to be healthier. In other words, people might work hard to persuade their partners to be healthy, thereby convincing themselves of the positive health benefits of being healthy as well (Briñol, McCaslin, \& Petty, 2012).

Notably, only one marginally significant result emerged for self-motivations in this study. We are cautious in interpreting marginal effects; in this case, we see a trend such that individuals reported greater relationship satisfaction when partners reported greater healthy self-motivation. This finding for self-motivation highlights the importance of studying the intrapersonal and relational context of health motivations. As to why there were not significant self-motivation findings in this study, it is possible that the partner and relationship motivations included in the model were stronger predictors of the outcomes measured. Similarly, if we had measured health behavior changes, which are more typical in SDT research, it is also possible that additional self-motivations could have emerged. Regardless, in trying to identify the motives behind adoption of healthy behavior, these findings suggest that SDT should be augmented to include the influence of significant others as a salient and influential external source of healthy behavior motivation.

\section{UNHEALTHY RELATIONSHIP MOTIVATIONS}

Individuals reported lower well-being and lower relationship satisfaction as their belief that their relationship was a source of unhealthy motivation increased. Perhaps individuals who experience lower relationship satisfaction and well-being are placing the blame for their unhealthy behaviors on their relationship in an attempt to avoid negative attributions for their partner or themselves. We turn to our operationalization of healthy and unhealthy motivations for further explanation. Because self-determination theory conceptualizes motivation as having the potential for different effects depending on a person's attributions about the source of that motivation, when posing the questions about motivations, we separated out the relationship from the partner and the self as unique sources of motivation. Considering the potential for these distinct source attributions along with interdependence theory's notion of relationship transformations provides some insight into why a person's relationship can be an unhealthy motivation when their partner is not.

If a person receives specific messages from a partner that encourage unhealthy behaviors, they would likely consider their partner a source of unhealthy 
motivation. On the other hand, if the person engages in unhealthy behaviors as a relationship activity (e.g., because they enjoy doing unhealthy activities together, as the variable is operationalized), a relationally motivated unhealthy behavior may take on a different relational tone than partner motivation. Therefore, because of the nature of the measures, these findings begin to tell a story about the importance of considering the partner and the relationship as separate when understanding internal and external motivations. In regards to the current study, people with lower well-being and in less satisfying relationships are not necessarily attributing unhealthy behaviors to their partners, but they may find that unhealthy behaviors are embedded within relationship activities or routines. This latter reason, citing a relationship as a reason for healthy and unhealthy motivations, may be interpreted as a strategy of routine relationship maintenance, in which people in relationships often align their activities, attitudes, and behaviors (Canary \& Stafford, 1992). Indeed, there is evidence of couples recognizing the natural alignment of their food, exercise, and weight with their partners over time (Bove, Sobal, \& Rauschenbach, 2003; Craig \& Truswell, 1990).

\section{THEORETICAL AND PRACTICAL IMPLICATIONS}

Considering self-determination theory or interdependence theory separately would have truncated what we believe is a larger and more complex picture of dyadic health motivation for people in romantic relationships. Self-determination theory provided the basis for understanding how different sources of internal or external motivation may co-occur to predict well-being; yet for people in interdependent relationships, other-motivated changes may be most relevant for understanding relationship quality and well-being. When taken together, this study provides initial evidence that some of the constructs from these theories may be intertwined to create a dyadic model of health motivation for people in relationships. Considering multiple sources of external motivations (i.e., the partner and the relationship as separate, but related external motivations), in addition to self-motivation, seems to be relevant in theorizing about healthy and unhealthy motivation. The evolution of this model in future research could enhance our understanding of interpersonal health communication processes.

From a health promotion standpoint, these initial findings are relevant in better tailoring messages and interventions to meet the needs of diverse motivations. Relationship therapists and health practitioners may benefit from joined efforts to improve people's health and relationship satisfaction simul- taneously, accounting for how they attribute their motivations or needs and the communication about health behaviors between relational partners.

\section{STRENGTHS AND LIMITATIONS}

The study has a number of strengths, including the use of a large sample of people in relationships, dyadic modeling for interpersonal and intrapersonal effects, and employing two theoretical perspectives to investigate a dynamic psychosocial process. By incorporating theoretical constructs from self-determination theory (Deci \& Ryan, 2008) and interdependence theory (Thibaut \& Kelley, 1959), the current study explores how personal and relational health motivation sources are associated with relationship satisfaction and well-being. One notable limitation is the lack of previous research connecting health motivations to outcomes such as well-being and relationship satisfaction in order to guide specific predictions. The study's cross-sectional design prohibits us from drawing any causal conclusions; therefore, we recognize the importance of future longitudinal dyadic research. Other limitations of the current study include the use of predominantly opposite-sex relational partners and the simplicity in the items used to operationalize healthy and unhealthy sources of motivation. To our knowledge, constructs related to self, partner, and relationship motivations for healthy and unhealthy behaviors have not been measured in previous research. These findings may serve as a starting point for future scale development research and eventually theory development.

\section{CONCLUSIONS}

The present study advances current theorizing with regard to health motivation in several important ways. First, we included the concept of unhealthy motivations. Previous research has focused on reasons why people tend to engage in or maintain healthy activities, with little emphasis on the potential importance of unhealthy behaviors. Within the context of relationships, we found indications that unhealthy motivations are relevant to study in regards to personal well-being and relationship satisfaction. In addition, the perspective of one's romantic partner as a source of motivation seems especially relevant, as people in relationships often report attempting to influence each other's health behaviors (Lewis \& Butterfield, 2007). The results presented here provide support for understanding motivation as a multi-dimensional, relational process. By conceptualizing one's partner or relationship as an external motivator for healthy and unhealthy decisions, the data show a clear pattern favoring extrinsic motivation for healthy and
Healthy and unhealthy motivations 
unhealthy behaviors in their association with relationship satisfaction and well-being.

\section{REFERENCES}

Bove, C. F., Sobal, J., \& Rauschenbach, B. S. (2003). Food choices among newly married couples: Convergence, conflict, individualism, and projects. Appetite, 40, 25-41. doi: 10.1016/S01956663(02)00147-2

Valerie J. Young, Tricia J. Burke

Boyd, M. P., Weinmann, C., \& Yin, Z. (2002). The relationship of physical self-perceptions and goal orientations to intrinsic motivation for exercise. Journal of Sport Behavior, 25, 1-18.

Briñol, P., McCaslin, M. J., \& Petty, R. E. (2012). Self-generated persuasion: Effects of the target and direction of arguments. Journal of Personality and Social Psychology, 102, 925-940. doi: 10.1037/ a0027231

Burke, V., Beilin, L. J., Dunbar, D., \& Kevan, M. (2004). Changes in health-related behaviors and cardiovascular risk factors in young adults: Associations with living with a partner. Preventive Medicine, 39, 722-730.

Burke, T. J., \& Segrin, C. (2016). Weight-related social control and relationship quality: Accuracy and bias effects. Journal of Social and Personal Relationships, 33, 999-1017. doi: 10.1177/0265407515615692

Canary, D. J., \& Stafford, L. (1992). Relational maintenance strategies and equity in marriage. Communication Monographs, 59, 243-267. doi: 10.1080/03637759209376268

Centers for Disease Control and Prevention. (2015, August 10). Heart disease facts. Retrieved from www.cdc.gov/heartdisease/facts.htm.

Craig, P. L., \& Truswell, A. S. (1990). Dynamics of food habits of newly married couples: Weight and exercise patterns. Australian Journal of Nutrition and Dietetics, 47, 42-46.

Deci, E. L., \& Ryan, R. M. (1985). Intrinsic motivation and self-determination in human behavior. New York: Plenum Press.

Deci, E. L., \& Ryan, R. M. (2008). Self-determination theory: A macrotheory of human motivation, development, and health. Canadian Psychology, 493, 182-185.

Dunsmore, S., \& Goodson, P. (2006). Motivation for healthy behavior: A review of health promotion research. American Journal of Health Education, 37, 170-183.

Hong, T. B., Franks, M. M., Gonzalez, R., Keteyian, S. J., Franklin, B. A., \& Artinian, N. T. (2005). A dyadic investigation of exercise support between cardiac patients and their spouses. Health Psychology, 24, 430-434.

Kelley, H. H., \& Thibaut, J.W. (1978). Interpersonal relations: A theory of interdependence. New York: Wiley.
Kenny, D. A., Kashy, D. A., \& Cook, W. L. (2006). Dyadic data analysis. New York: Guilford Press.

Lewis, M. A., \& Butterfield, R. M. (2007). Social control in marital relationships: Effect of one's partner on health behaviors. Journal of Applied Social Psychology, 37, 298-319.

Markey, C. N., Markey, P. M., \& Gray, H. F. (2007). Romantic relationships and health: An examination of individuals' perceptions of their partner's influences on their health. Sex Roles, 57, 435-445.

Mata, J., Silva, M. N., Vieira, P. N., Carraca, E. V., Andrade, A. M., Coutinho, S. R., Sardinha, L. B., \& Teixeira, P. J. (2009). Motivational "spill-over" during weight control: Increased self-determination and exercise intrinsic motivation predict eating self-regulation. Health Psychology, 28, 709716.

Moreno, J. A., Gonzalez-Cutre, D., Martin-Albo, J., \& Cervello, E. (2010). Motivation and performance in physical education: An experimental test. Journal of Sports Science and Medicine, 9, 79-85.

Powell, C., \& Van Vugt, M. (2003). Genuine giving or selfish sacrifice? The role of commitment and cost level upon willingness to sacrifice. European Journal of Social Psychology, 33, 403-412.

Rusbult, C. E., Arriaga, X. B., \& Agnew, C. R. (2001). Interdependence in close relationships. In G. J. O. Fletcher \& M. S. Clark (eds.), Blackwell handbook of social psychology: Interpersonal processes (pp. 359-387). Oxford, England: Blackwell.

Rusbult, C. E., Martz, J. M., \& Agnew, C. R. (1998). The investment model scale: Measuring commitment level, satisfaction level, quality of alternatives, and investment size. Personal Relationships, 5, 357-391.

Sebire, S. J., Standage, M., \& Vansteenkiste, M. (2009). Examining intrinsic versus extrinsic exercise goals: Cognitive, affective and behavioral outcomes. Journal of Sport \& Exercise Psychology, 31, 189-210.

Thibaut, J. W., \& Kelley, H. H. (1959). The social psychology of groups. New York: Wiley.

Treiber, F. A., Baranowski, T., Braden, D. S., Strong, W. B., Levy, M., \& Knox, W. (1991). Social support for exercise: Relationship to physical activity in young adults. Preventive Medicine, 20, 737-750.

Van Lange, P. A. M., Rusbult, C. E., Drigotas, S. M., Arriaga, X. B., Witcher, B. S., \& Cox, C. L. (1997). Willingness to sacrifice in close relationships. Journal of Personality and Social Psychology, 72, 1373-1395.

Ware, J. E., \& Sherbourne, C. D. (1992). The MOS 36item Short-Form health Survey (SF-36): I. Conceptual framework and item selection. Medical Care, 30, 473-483. 